\title{
Disco de Newton com LEDs
}

\author{
Newton's disk with LEDs
}

\author{
M V Silveira, R B Barthem
}

Instituto de Física, Universidade Federal do Rio de Janeiro, Rio de Janeiro, RJ, Brasil

\begin{abstract}
Recebido em 13 de abril de 2016. Revisado em 11 de maio de 2016. Aceito em 15 de maio de 2016
\end{abstract}
Há muitos anos que o chamado "disco de Newton" vem sendo usado no ensino de óptica na tentativa de ilustrar o mecanismo da percepção espectral da luz visível pelo olho humano. Sua proposta é de que, ao ser girado, aparente ter a cor branca, que é a soma de todas as cores do espectro nele estampadas. De fato, a cor resultante que se percebe é um tom de cinza, visto que neste caso ocorre uma síntese subtrativa. A proposta desse trabalho é construir um disco, como o de Newton, no qual podemos compor através de LEDs coloridos não apenas a cor branca, como também a amarela, a ciano e a magenta. Dessa vez, as cores são geradas através da síntese aditiva com base na teoria tricromática de Young-Helmholtz. Palavras-chave: Disco de Newton, LED, Young-Helmholtz.

For many years, the so-called "Newton's disc" has been used in optical teaching in an attempt to illustrate the human eye's mechanism of spectral perception of visible light. His proposal is, when rotated, appears to be white, which is the sum of all colors of the spectrum printed on it. In fact, the resulting color we see is a shade of gray, as in that case there is a subtractive synthesis. The purpose of this work is to build a disc, such as Newton's one, in which we can compose through colored LEDs not only white color, as also yellow, cyan and magenta. This time, colors are generated by additive synthesis based on the Young-Helmholtz trichromatic theory.

Keywords: Newton's disk, LED, Young-Helmholtz.

\section{Introdução}

A simples ação de abrir os olhos e enxergar o mundo carrega consigo uma série de fenômenos que podem ser utilizados para auxiliar no ensino de vários campos da ciência. A luz, enquanto onda eletromagnética, propaga-se no vácuo a uma velocidade de cerca de $300.000 \mathrm{~km} / \mathrm{s}$. Para visualização dos objetos que estão ao nosso redor, isso implica em um tempo de propagação às nossas células fotorreceptoras de cerca de algumas dezenas de nanossegundos $\left(\Delta \mathrm{t} \sim 10^{-8} \mathrm{~s}\right)$. Alguns dos processos bioquímicos que se sucedem, no entanto, não são tão velozes. O processo bioquímico se inicia quando a opsina (pigmento contido nos cones e bastonetes) ligada à vitamina $\mathbf{A}$ recebe um fóton e sofre uma mudança física (sis $\rightarrow$ trans). Essa mudança ocorre em apenas alguns picossegundos $\left(\Delta \mathrm{t} \sim 10^{12} \mathrm{~s}\right)$. Os pro-

*Endereço de correspondência: marcio.vs@oi.com.br cessos seguintes, que vão da geração e propagação do impulso elétrico pelo sistema nervoso ao reconhecimento da imagem no cérebro, levam bem mais tempo, da ordem do décimo de segundo $\left(\Delta \mathrm{t} \sim 10^{-1} \mathrm{~s}\right)$ [1]. O tempo necessário para que o estímulo criado na retina desapareça foi descrito pelo médico Peter Mark Roget em 1826, e medido pela primeira vez pelo físico Joseph-Antoine Plateau em 1829. É o que ficou conhecido como sendo a persistência retiniana [2].

Os efeitos decorrentes da duração temporal de cada etapa do processo da visão são irrelevantes para as situações do dia a dia, tornando nossa visão perfeitamente adaptável ao meio em que vivemos. No entanto, aproveitando-se de algumas de suas consequências, foi possível simular uma sequência contínua através da sobreposição de imagens ao longo do tempo, surgindo assim a cinematografia [3]. 
Para que a projeção de um filme se assemelhe a sensação visual que possuímos no mundo real, é fundamental o equilíbrio entre três aspectos da amostragem temporal, ou seja, entre três aspectos envolvidos na sobreposição de cada quadro de imagem. O primeiro deles é a remanência visual, que é o tempo em que as imagens são trocadas. Esse deve ser inferior ao da capacidade de nosso sistema visual em detectar o momento dessa troca de forma a nos levar a acreditar que se trata de um movimento contínuo (em torno de 24 quadros por segundo). Os outros aspectos são a cintilação e o batimento e/ou interferências com a rede de distribuição elétrica. Esse último é mais inerente aos sistemas eletrônicos [4]. Portanto, a velocidade em que os quadros são trocados ao longo do tempo permite sensibilizar nossa visão de forma a produzir sensações e efeitos que são utilizados em muitas aplicações do nosso cotidiano.

Isaac Newton (1643-1727) estudou profundamente a propriedade de dissociação da luz branca, ao atravessar um prisma de vidro, em feixes de luzes de diversas outras cores. Newton teria encontrado sete cores, coincidência ou não, o mesmo número das notas musicais. No segundo problema da $6^{a}$ proposição do seu livro Optics, na edição de 1730 [5], Newton utiliza um círculo com sete fatias, como uma pizza, propondo que cada uma das sete fatias represente uma das sete cores observadas, a saber: vermelha, laranja, amarela, verde, azul, anil e violeta. Usando uma forma de cálculo geométrico, Newton descreve as cores resultantes a partir da combinação das sete cores que ele considerou como sendo primárias. Em certo momento Newton, ao descrever a composição de duas cores, afirma:

“... todavia a cor composta dessas duas não será perfeitamente branca, mas alguma cor anônima esmaecida. Pois ainda não fui capaz de produzir o branco perfeito misturando apenas duas cores primárias. Se ele pode ser composto de uma mistura de três (cores) tomadas a distâncias iguais na circunferência, não sei; mas de quatro ou cinco, não duvido que pode..."

Havia muitas dúvidas pairando na cabeça de Newton e, para nós, não fica claro se ele fazia uso do que chamamos atualmente de "disco de Newton". Esse disco é dividido tal qual o citado anteriormente, mas pintado com as sete cores básicas e posto a girar pelo seu centro de gravidade. O efeito provocado pela rotação rápida deveria compor a cor branca, que seria como convergir em um único ponto as sete cores do prisma. Na verdade, nunca conseguimos o branco, mas uma tonalidade de cinza. Isso se deve ao fato de que cada um dos setores coloridos está absorvendo a parte espectral da luz complementar à que espalha, isto é, a da sua cor. No tradicional "disco de Newton" estamos trabalhando com a síntese subtrativa de cores e não a aditiva. A síntese aditiva de cores seria a convergência do espectro decomposto por um prisma em um único feixe, como fez Newton.

Com o propósito de compor o branco usando um disco em movimento, ao invés de se fazer uso da síntese subtrativa, foi desenvolvido um aparato usando LEDs de três cores; vermelha, verde, e azul, ou seja o padrão RGB (Red, Green, Blue). Este padrão de cores corresponde à teoria tricromática de Young-Helmholtz, na qual é proposto que nossa visão cromática é formada por células denominadas por cones. São três os tipos de cones e cada um deles é responsável por produzir uma resposta neurológica a partir da estimulação por luzes nas regiões espectrais de cada uma dessas três cores [6]. As demais cores podem ser percebidas por luzes monocromáticas, em determinadas posições do espectro, ou por sensibilizações combinadas em intensidades diferentes dessas três cores fundamentais. A Figura 1 apresenta uma descrição padrão para as respostas espectrais de cada um dos cones $(S, M, L)$ e as funções $(\bar{x}, \bar{y}, \bar{z})$ que representam as percepções fisiológicas padrão da visão humana em cores estabelecidas pela Commission Internationale de l'Éclairage em 1931, através do CIE $19312^{\circ}$ Standard Observer [7]. Para uma discussão detalhada desses espaços de cores, sugerimos o trabalho de Mark Q. Shaw feito em sua tese de M.Sc. no Center of Imaging Science Rochester Institute of Technology [8] Além disso, foram incluídas nessa figura, para efeito de comparação, as curvas espectrais das emissões dos LEDs vermelho $(\mathbf{R})$, verde $(\mathbf{G})$ e azul (B) [9].

Usando dois pares de LEDs de cada uma dessas três cores e fazendo-os girar sobre um eixo central, estando todos os seis LEDs à mesma distância do centro, mostra-se que é possível compor não só o branco como também as demais cores que podem ser obtidas pela síntese aditiva de luzes nas três cores básicas. A síntese aditiva é mais comumente entendida através de um diagrama, como o apre- 


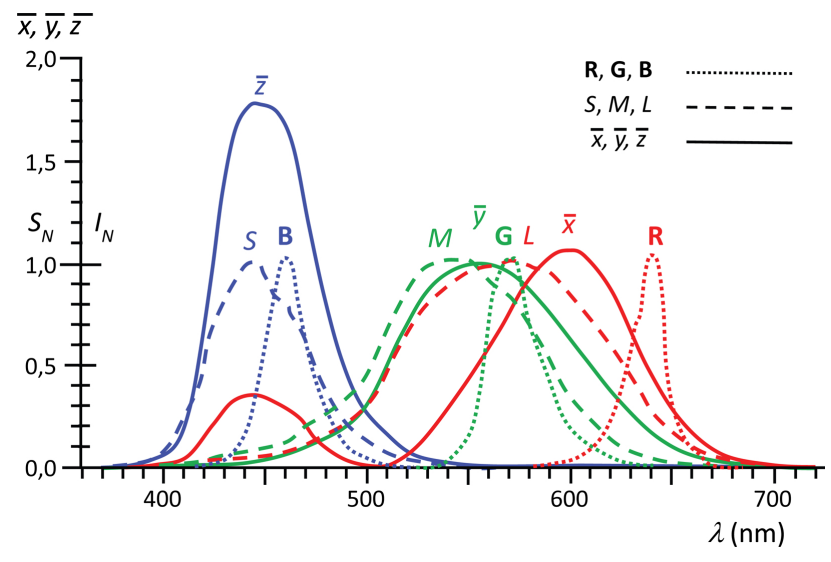

Figura 1: Gráfico das respostas espectrais dos cones e de emissão dos LEDs RGB. As intensidades normalizadas $I_{N}$ das emissões dos LEDs azul (B), verde $(\mathbf{G})$ e vermeIho $(\mathbf{R})$ estão representadas em linhas pontilhadas [9]. Em tracejado estão representadas as respostas espectrais para as sensibilidades normalizadas $S_{N}$ dos três cones $(S \leftrightarrow$ azul, $M \leftrightarrow$ verde e $L \leftrightarrow$ vermelho) [6]. Em contínuo estão as funções $\bar{x}(\lambda), \bar{y}(\lambda)$ e $\bar{z}(\lambda)$ que representam as percepções fisiológicas padrão da visão humana em cores estabelecida pela Commission Internationale de l'Éclairage em 1931 através do CIE $19312^{\circ}$ Standard Observer [7].

sentado na Figura 2. Nele podemos observar que na sobreposição de duas cores de luzes ocorre a formação de uma terceira. A convergência das três cores, vermelho, verde e azul, produz a luz branca.

\section{Arranjo Experimental}

O aparato proposto pode ser construído por uma pessoa com conhecimentos básicos de eletrônica e alguma habilidade manual, podendo ser o professor ou um estudante mais interessado sob sua supervisão. O material e as ferramentas utilizadas são descritos na Tabela 1.

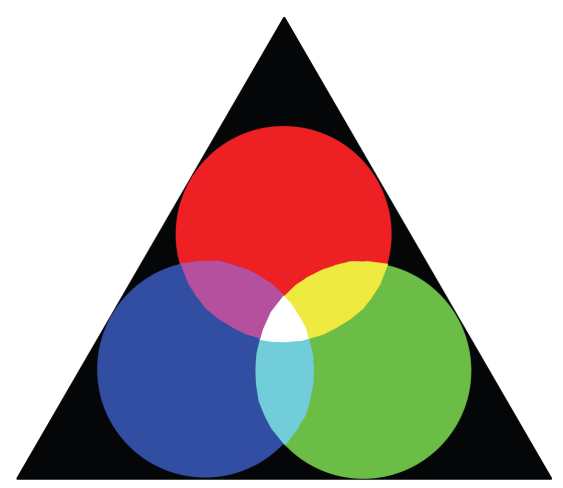

Figura 2: Composição aditiva de cores.
A montagem é baseada no uso de dois CD's unidos, para aumentar a rigidez do sistema, o qual pode ficar fragilizado pelas perfurações. A marcação dos furos e o posicionamento dos componentes são feitos com a ajuda do mecanismo da unidade óptica que proporciona o movimento de rotação do CD. Começaremos, portanto, com a descrição o sistema de rotação.

Podemos obter o motor indicado para a montagem em uma unidade óptica de um aparelho de som de CD ou um reprodutor de vídeos em DVD. Os leitores de CD/DVD utilizados em computadores não servem, pois não operam com corrente contínua. O motor da unidade óptica que foi usado, código RF310T-11400, opera, segundo especificação técnica, a 5,9VDC. Outro motor, mais comum em aparelhos de DVD é o RF-300F A-12350, também operando a $5,9 \mathrm{~V}$, e que pode ser encontrado no mercado por menos de $\mathrm{R} \$ 20,00$. A unidade óptica utilizada foi produto de sucata, já que sua cabeça de leitura óptica estava com defeito, dano que costuma ser mais frequente. Como o motor estava íntegro, a unidade foi desmontada para retirada somente deste motor e a estrutura metálica que lhe suporta.

Essa estrutura, com o motor, deve ser presa a uma placa de madeira de aproximadamente $16 \mathrm{~cm}$ de altura por $8 \mathrm{~cm}$ largura e $1 \mathrm{~cm}$ de espessura. No caso de se utilizar a estrutura metálica que suporta o motor, basta fixá-la por meio de dois parafusos próprios para madeira, como pode ser visto na Figura 3a. Como fonte de alimentação pode ser utilizado um carregador de celular que forneça entre 6 e $9 \mathrm{~V}$ DC e pelo menos $200 \mathrm{~mA}$. Em nosso projeto, utilizamos um carregador de celular de $6,4 \mathrm{~V}$ e 200 $\mathrm{mA}$.

Adicionamos uma chave interruptora $\left(C h_{0}\right)$ e um potenciômetro $\left(P_{0}\right)$ de $5 \mathrm{k} \Omega 4 \mathrm{~W}$ para variar a tensão sobre o motor, controlando assim, sua velocidade de giro. Desse modo, evitam-se rotações muito altas do disco, que poderiam comprometer a segurança. Em funcionamento, a tensão máxima aplicada ao motor cai para $5,24 \mathrm{~V}$, sendo percorrido por uma corrente de $32 \mathrm{~mA}$. O sistema de rotação pode ser visto nas Figuras 3a e 3b e o esquema elétrico na Figura 3c.

A montagem do circuito é feita sobre um CD, ou seja, todos os componentes são bem fixados e colados neste CD para que, quando em movimento, não se soltem e não sejam arremessados, o que poderia provocar acidentes. Outra opção seria fixar no CD apenas os LEDs. Nessa segunda opção de monta- 
Tabela 1: Lista do material e equipamentos necessários para a montagem.

\begin{tabular}{lll}
\hline Sigla & Quant & Descrição \\
\hline $\mathrm{R}$ & 2 & LED vermelho de $5 \mathrm{~mm}$ e alto brilho \\
$\mathrm{G}$ & 2 & LED verde de $5 \mathrm{~mm}$ e alto brilho \\
$\mathrm{B}$ & 2 & LED azul de $5 \mathrm{~mm}$ e alto brilho \\
$\mathrm{R}_{1}-\mathrm{R}_{2}-\mathrm{R}_{3}$ & 3 & Resistores de $100 \Omega 1 / 8 \mathrm{~W}$ \\
$\mathrm{Ch}$ & 1 & Chave interruptora (liga e desliga) \\
$\mathrm{Ch}_{1}-\mathrm{Ch}_{2}-\mathrm{Ch}_{3}$ & 3 & Mini chaves interruptoras (liga e desliga) \\
$\mathrm{P}$ & 1 & Potenciômetro de fio $4 \mathrm{~W}, 5 \mathrm{k} \Omega$ \\
$\mathrm{P}_{1}-\mathrm{P}_{2}-\mathrm{P}_{3}$ & 3 & Trimpot multivolta 3006 de $2 \mathrm{k} \Omega$ \\
$\mathrm{V}_{1}-\mathrm{V}_{2}-\mathrm{V}_{3}$ & 3 & Suportes com baterias CR $2032(3,0 \mathrm{~V})$ \\
& $1,5 \mathrm{~m}$ & Fios cabinhos de cores variadas \\
& 1 & Bastão de cola quente \\
& 1 & Ferro de solda \\
$\mathrm{M}$ & $20 \mathrm{~cm}$ & Fio de solda \\
$\mathrm{V}$ & 1 & Rolo de fita isolante. \\
& 1 & Motor de CD ou DVD (motor e polia $)$ \\
& 1 & Fonte de tensão contínua $6 \mathrm{~V}, 200 \mathrm{~mA}$ \\
& 1 & Transferidor \\
& 1 & Caneta marca CD \\
& 1 & Lixa de madeira fina 100 \\
& 1 & Cola instantânea (acrílica) \\
& 2 & Brocas de metal de 2 e $5 \mathrm{~mm}$ \\
& 2 & CD ou $D V D$ \\
& 1 & Mini furadeira \\
& 2 & Parafusos de madeira $3,5 \mathrm{x} 12 \mathrm{~mm}$ \\
\hline &
\end{tabular}

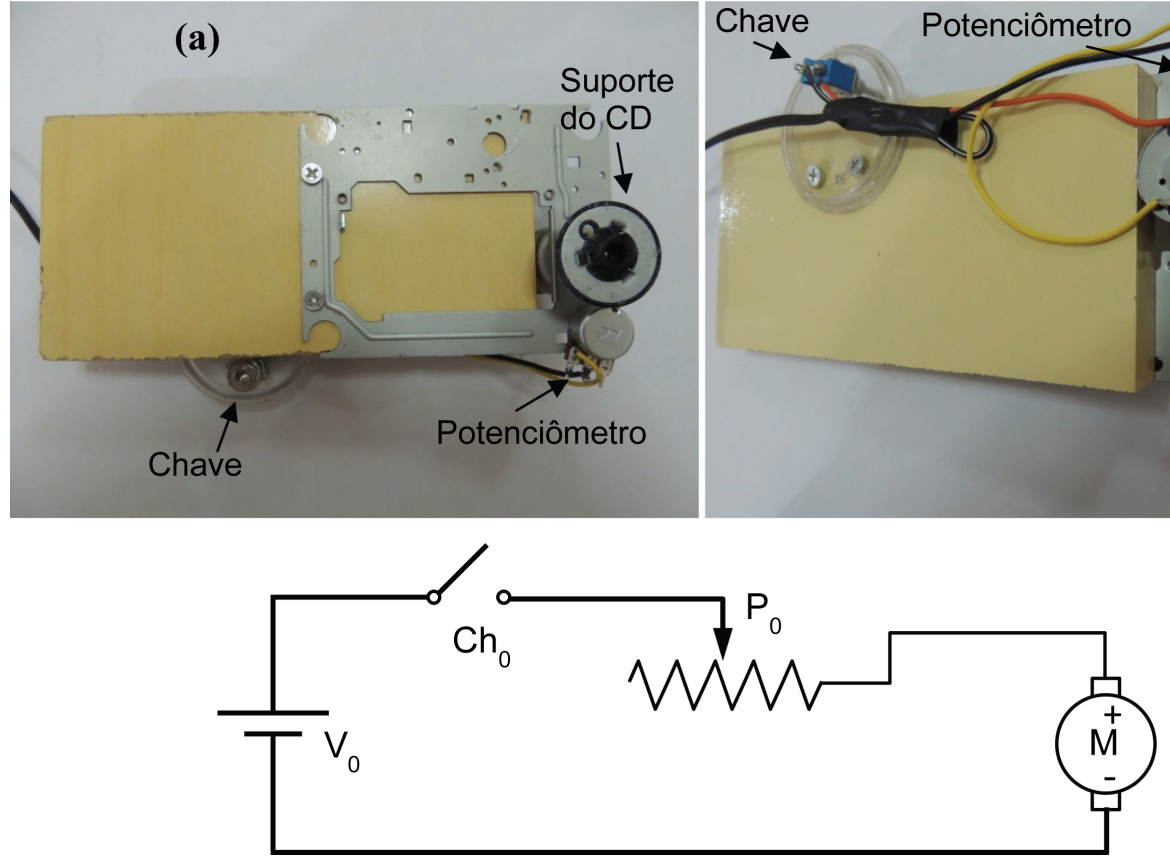

(b)

(c)

Figura 3: Sistema de rotação. (a) O mecanismo da unidade óptica preso a uma placa de madeira e o interruptor abaixo à esquerda. (b) Parte posterior do mecanismo mostrando o potenciômetro, o interruptor e as ligações elétricas. (c) Diagrama da montagem elétrica da alimentação do motor.

gem, todo o restante do circuito, incluindo resistores, chaves, potenciômetros e fonte de alimentação, localizar-se-iam fora do CD. A ddp fornecida por cada um dos três circuitos teria de ser transmitida para o CD em movimento de forma independente. A razão para não optarmos por este tipo de montagem é que a possibilidade de haver pontos de mau contato cresceria de forma considerável, tornando o 
projeto sujeito a ajustes frequentes e aumentando muito o nível de complexidade em sua construção.

No projeto desenvolvido, portanto, fixamos todos os componentes eletrônicos no próprio $\mathrm{CD}$, reduzindo a possibilidade de mau contato. A preocupação, neste caso, é com a distribuição simétrica de todos os componentes eletrônicos. Uma distribuição simétrica e cuidadosa evita que o CD fique com um problema grave de balanceamento, o que pode inviabilizar o projeto.

No início da montagem do disco, é utilizado um transferidor e uma caneta própria para CD para fazer as marcações das posições dos LEDs. Eles precisam estar perfeitamente distribuídos para que o traço, por eles formado, seja homogêneo e com apenas uma faixa cromática. Como são seis LEDs ao todo, cada um fica a uma distância angular de $60^{\circ}$ do seu vizinho (Figura 4a). Tomando o centro do CD como ponto médio, os pontos feitos nas bordas são ligados dois a dois, tomando-se o cuidado para que todos estes traços realmente passem pelo centro do
CD (Figuras 4b, 4c). Caso haja alguma imprecisão é preciso limpar os traços com álcool e reiniciar o processo. A precisão nesta etapa irá garantir que o produto final funcione corretamente.

Além dos seis pontos marcados nas extremidades do CD, marca-se também um ponto a uma distância de $1 \mathrm{~cm}$ de sua borda (Figura 4d). Na sequência, é usado o mecanismo da unidade óptica, que foi descrito anteriormente, para fixá-lo e fazê-lo girar (Figura 4e). Girando o disco manualmente, colocase a caneta sobre a posição indicada pelo ponto marcado anteriormente, na intenção de traçar um círculo o mais perfeito possível e simetricamente distante do centro. Com o traço marcado o CD dever ser desencaixado do suporte para a etapa seguinte.

Os suportes de baterias são distribuídos simetricamente ao redor do centro do CD e seus terminais marcados com a caneta. Um " $\mathrm{x}$ " deve ser feito para assinalar todas as 12 posições que devem ser perfuradas. Antes de iniciar a furação, no entanto, o
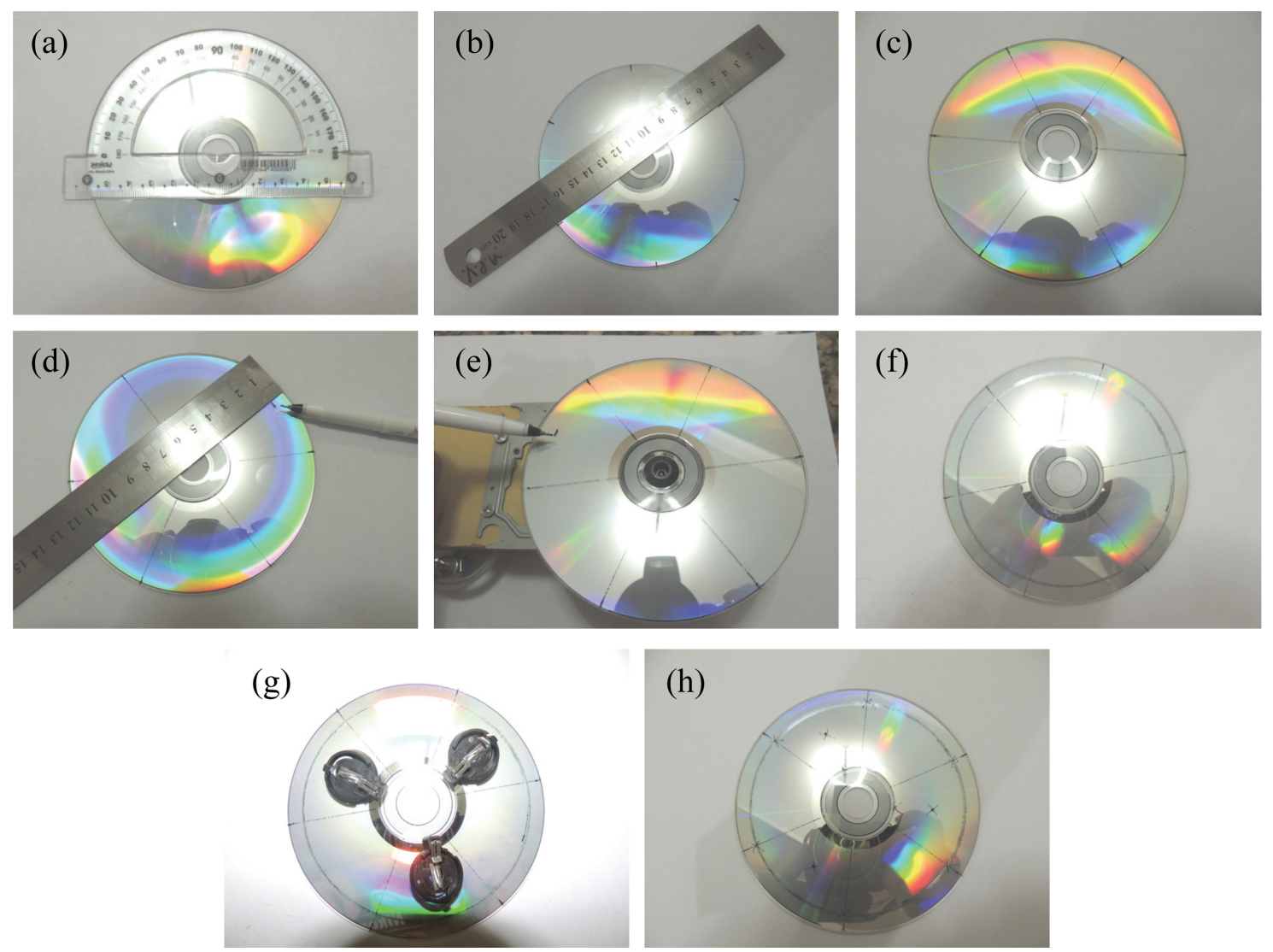

Figura 4: Preparação do CD. (a) Transferidor sobre o CD para marcação dos ângulos de $60^{\circ}$. (b) e (c) Ligação dos pontos complementares colineares. (d) Marcação do ponto distante a $1 \mathrm{~cm}$ da margem do CD. (e) Pondo o CD a girar com a caneta sobre o ponto marcado. (f) Círculo marcado no CD. (g) Marcação da furação dos suportes de bateria. (h) Marcação com " $x$ " de todas as posições onde serão perfuradas. 
segundo CD deve ser colado sobre o primeiro de forma centralizada utilizando a cola instantânea.

Estando as marcações definidas, é utilizada uma broca de metal de $2 \mathrm{~mm}$ para fazer o furo inicial e, em seguida, uma de $5 \mathrm{~mm}$ para alargar cada furo ao diâmetro do LED e, se necessário, dos suportes de baterias.

A etapa seguinte é a montagem e soldagem dos componentes eletrônicos no CD a partir de um circuito simples. O circuito, na verdade, é a composição de três circuitos independentes, com chaves interruptoras e alimentações próprias. Em cada circuito é colocado um potenciômetro para possibilitar um ajuste fino na intensidade do brilho de cada par de LEDs. Essa possibilidade de variar o brilho dos LEDs permite que se consiga produzir a cor branca com maior pureza, além do amarelo, magenta e ciano. A Figura 5 descreve um diagrama com os três circuitos separados.

Antes de iniciar a montagem é necessário conferir se todos os LEDs e suportes se encaixam perfeitamente nos furos correspondentes do CD. Os LEDs devem ter suas cabeças lixadas de forma que suas superfícies fiquem bem planas para que as luzes sejam emitidas de forma mais difusas, lineares e menos direcionais. A direcionalidade se deve ao fato de cada LED possuir uma lente em seu topo, a qual deve ser removida pela lixa. Os LEDs devem ser fixados com cola quente, da mesma forma que os suportes.

De um lado do "sanduíche" de CD's são colocados os suportes de bateria. No outro lado são encaixados os LEDs, ficando a parte elétrica nessa face onde são feitas as conexões e soldagens, inclusive com o posicionamento dos resistores, potenciômetros e interruptores, de acordo com o esquema apresentado na Figura 5. Todos os componentes devem ser presos com cola quente de forma bem distribuída para que não afete o balanceamento do CD. É necessário um cuidado adicional para não prender nenhum componente próximo ao furo central do disco, área não metalizada. Sem esse cuidado o CD não se encaixa no suporte da unidade óptica. Os três interruptores são colados na borda externa do disco a fim de facilitar seu manuseio. Eles são distribuídos simetricamente, como pode ser visto na Figura 6a. Esses interruptores estão indicados pelas letras R, G e B, iniciais de Red, Green e Blue, conforme a Figura $6 \mathrm{~b}$.

Após o término da montagem são colocadas as três baterias e todo o sistema deve ser testado de forma a se verificar se não há nenhum ponto de solda
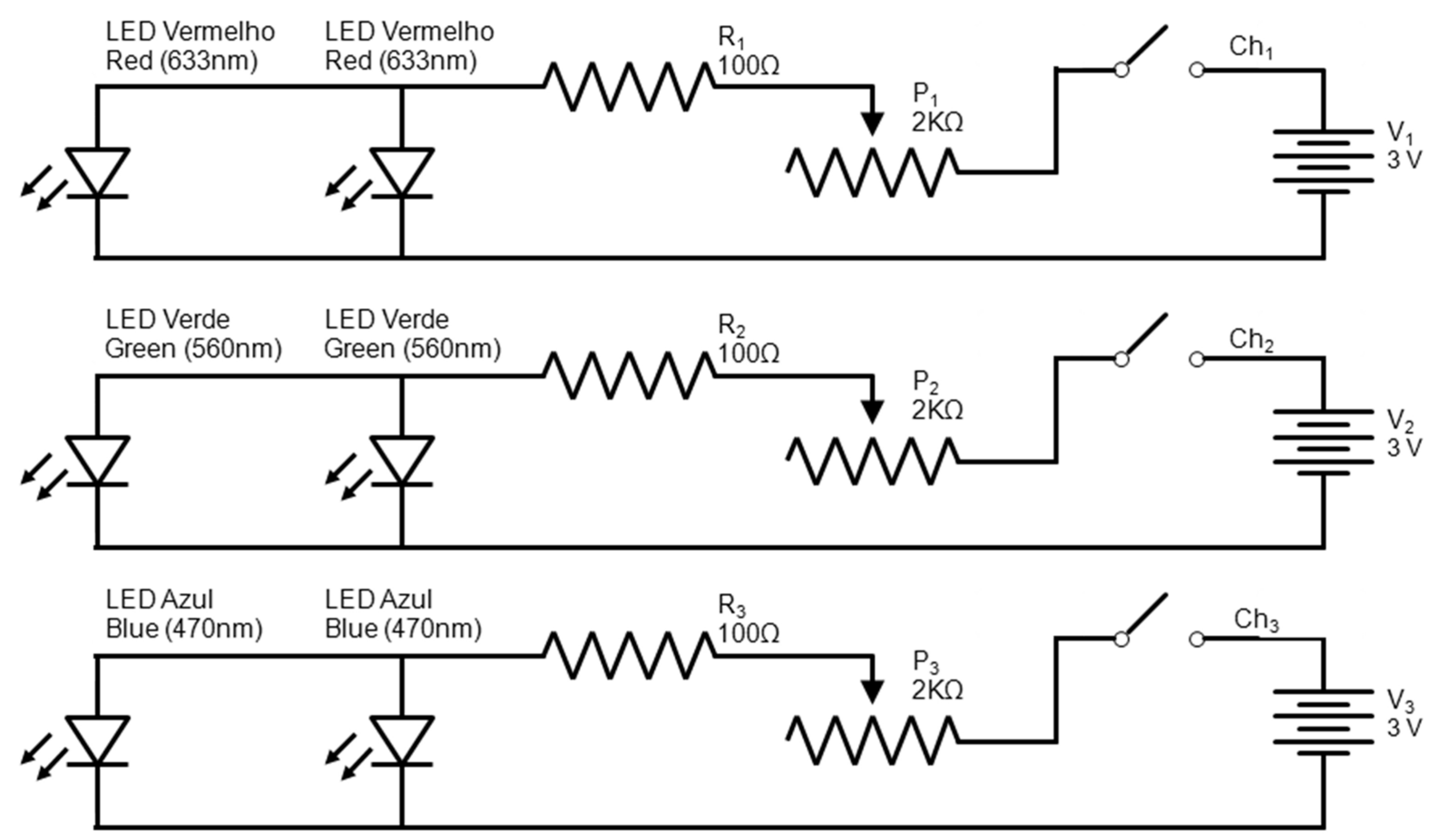

Figura 5: Circuitos eletrônicos para os três LEDs. $R_{1}, R_{2}$ e $R_{3}$ são três resistores cuja função é limitar a corrente e impedir que os LEDs sejam danificados. Os potenciômetros $P_{1}, P_{2}$ e $P_{3}$ têm a função de proporcionar um ajuste fino no brilho de cada par de LEDs. 

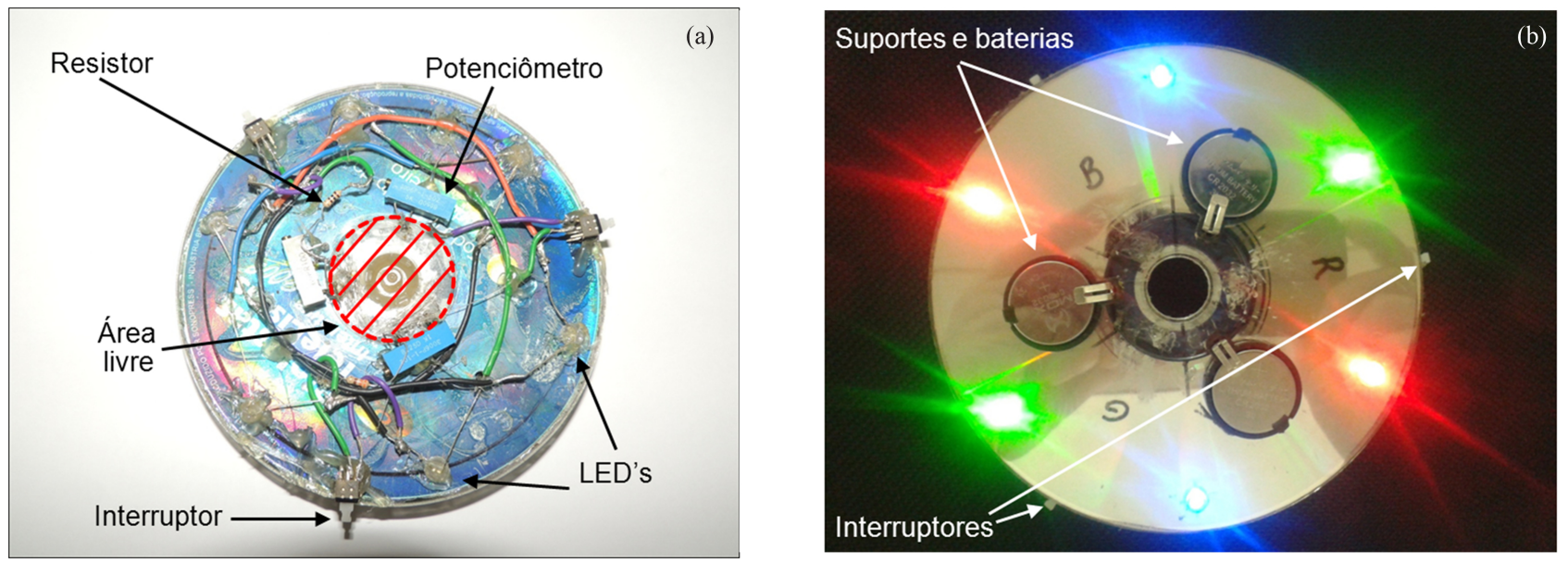

Figura 6: Montagem concluída. (a) Parte de trás do CD, onde se observam os componentes eletrônicos. (b) Parte de cima do CD com os seis LEDs acesos e as baterias acondicionadas devidamente em seus suportes. As posições dos conectores, que se encontram por trás do $C D$, estão assinaladas pelas letras $R, G, B$.

fria ou mau contato. $\mathrm{O}$ resultado da montagem pode ser visto nas Figuras 6a e 6b.

\section{Ajustes e Resultados}

Após a preparação do mecanismo da unidade óptica e do CD, tem início a fase de ajustes. Inicialmente o CD é fixado com cola quente no mecanismo da unidade óptica. Deve-se adicionar uma quantidade suficiente de cola quente para que ocorra uma boa fixação. Após a secagem da cola o $\mathrm{CD}$ pode ser posto a girar. Verifica-se, então, se todos os LEDs produzem um aro luminoso de espessura aproximadamente igual à espessura do LED e uma cor uniforme. Pode ocorrer de um ou mais LEDs precisarem ser redirecionados para corrigir sua distribuição ao longo do aro.

Após as correções iniciais, o próximo passo é tentar produzir a cor amarela com os LEDs vermelhos e verdes deixando, portanto, os LEDs azuis apagados (Figura 7a). Primeiro deve-se ajustar a posição do potenciômetro $\mathrm{P}_{2}$ dos LEDs verdes de forma que estes fiquem com um brilho bem intenso, mas sem atingir o seu valor máximo. $\mathrm{O}$ potenciômetro $\mathrm{P}_{1}$ deve ter seu valor ajustado para que os LEDs vermelhos fiquem com brilhos próximos, visualmente, aos dos verdes. Em seguida põe-se o conjunto a girar e observa-se a necessidade de aumentar ou reduzir o brilho dos LEDs vermelhos. Para isso para-se o disco, altera-se a posição do potenciômetro $\mathrm{P}_{1}$ e o disco é posto a girar novamente. $\mathrm{O}$ processo é repetido até que se consiga produzir a cor amarela (Figuras 7b e 7c). Caso chegue-se ao máximo de brilho dos
LEDs vermelhos sem que a cor resultante perca o aspecto esverdeado, deve-se reduzir a intensidade dos LEDs verdes pelo potenciômetro $\mathrm{P}_{2}$ e recomeçar o processo.

O passo seguinte é produzir o branco. Para tanto, todos os LEDs serão ligados (Figura 7d) e os LEDs azuis devem ter sua intensidade alterada através do potenciômetro $\mathrm{P}_{3}$ correspondente, repetindo o processo de parar o disco, alterar o potenciômetro e voltar a girar mais uma vez o disco até que se produza o branco (Figuras 7d, 7e, 7f). Após o ajuste, os valores finais para os potenciômetros, em nosso aparato, ficaram em torno de $12 \Omega$, para o potenciômetro $\mathrm{P}_{1}$ (LEDs vermelhos), $235 \Omega$ para o potenciômetro $\mathrm{P}_{2}$ (LEDs verdes) e $450 \Omega$, para o potenciômetro $\mathrm{P}_{3}$ (LEDs azuis). Esses valores podem variar muito em função das especificações técnicas dos LEDs e do estado de uso das baterias. Portanto, antes de iniciar a apresentação do experimento aos alunos, deve ser feita uma verificação prévia que indicará se o aparato ainda encontra-se calibrado. Caso contrário, os brilhos dos LEDs deverão se ajustados, seguindo os passos descritos anteriormente.

Com o sistema bem calibrado, o experimento permite compor a partir dos LEDs de cores vermelha, verde e azul, as cores amarela, magenta, ciano e branca. Como visto, na fase de ajustes, a cor amarela é produzida ao se ligar apenas os LEDs verdes e vermelhos (Figuras 7a, 7b, 7c). A cor branca é conseguida quando se ligam todos os LEDs, e pode ser observado nas Figuras 7d, 7e, 7f.

Para as demais cores, magenta e ciano, o procedimento é o mesmo, apenas alterando as posições dos 

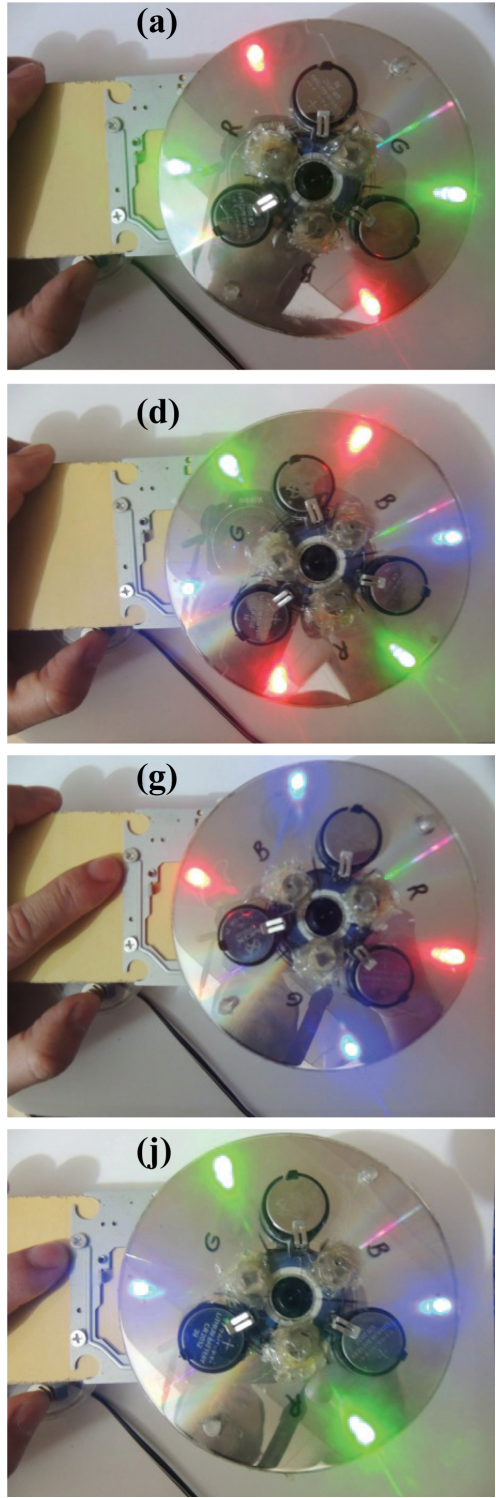
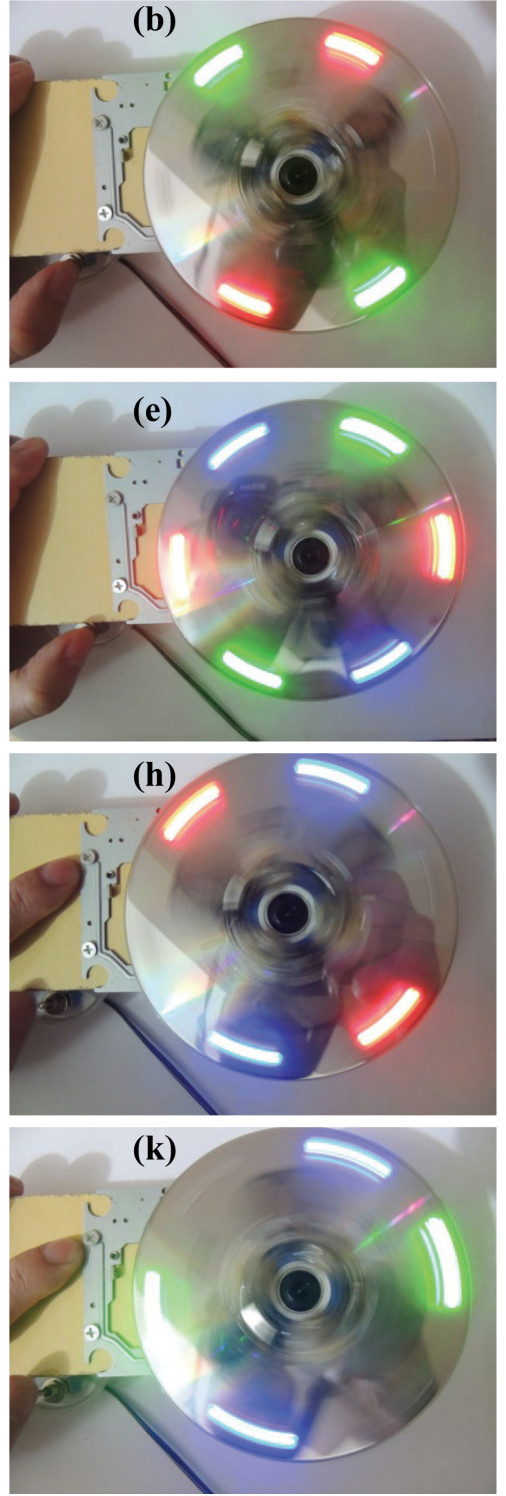
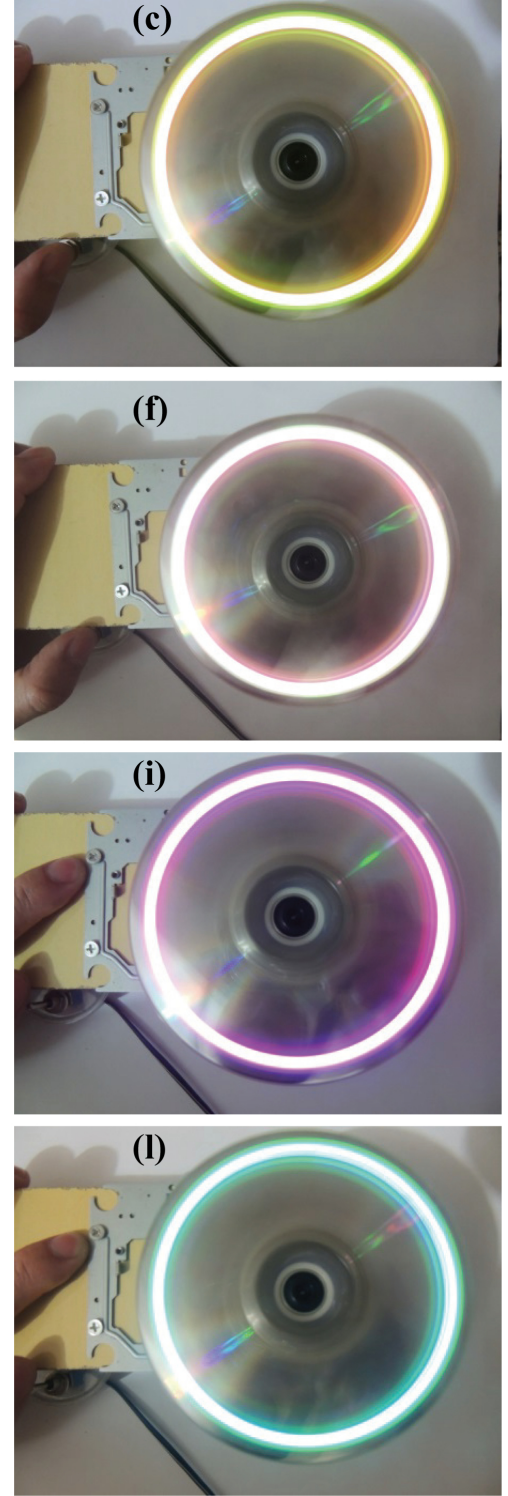

Figura 7: Ajuste fino para composição das cores. (a, b, c) Ajustes para produzir a cor amarela. (d, e, f) Ajuste para se produzir a cor branca. ( $g, h, i)$ Apenas os LEDs azuis e vermelhos são ligados, produzindo, quando em movimento giratório, a cor magenta. $(j, k, l)$ São acesos apenas os LEDs verdes e azuis que, ao girarem, produzem a cor ciano.

interruptores. Para compor a cor magenta, apenas os LEDs azuis e vermelhos devem ser ligados (Figuras $7 \mathrm{~g}, 7 \mathrm{~h}, 7 \mathrm{i})$. A cor ciano é obtida com apenas os LEDs azuis e verdes ligados. O resultado pode ser visto nas Figuras $7 \mathrm{j}, 7 \mathrm{k}, 7 \mathrm{l}$.

\section{Conclusão}

O chamado "disco de Newton" é muito empregado para demonstrar a síntese de cores no ensino de óptica. Ele é construído sobre um disco dividido em sete fatias, como as de uma pizza, e pintadas com cada uma das sete cores primárias estabelecidas por Newton. Esse disco, ao ser girado, parece ter a cor cinza, ao invés da branca. Isso traz um desconforto na relação entre a proposta do professor e o resultado observado pelos estudantes.

No experimento proposto neste trabalho, a composição da cor branca é obtida de fato. Apesar dos dois experimentos envolverem a rotação de discos para a composição de cores, tratam-se de sínteses diferentes; subtrativa para o disco de Newton e aditiva para o disco de LEDs. Além disso, é possível obter seis cores do espectro, além do branco, através do acionamento de LEDs de uma, duas ou três cores simultaneamente.

O aparato desenvolvido com LEDs permite a análise do funcionamento da visão humana, não 
só de suas características cromáticas como a da velocidade de captação e percepção das imagens. Essa compreensão é indispensável para a formação de cidadãos contemporâneos, capazes de compreender as tecnologias de imagem e cinema.

As fotografias utilizadas nas figuras contidas neste material apenas dão uma ideia do efeito, o qual pode ser percebido mais intensamente ao olharmos com nossos próprios olhos. Isso ocorre devido às características operacionais de aquisição que a câmera fotográfica possui, distintas das que se encontram na visão humana.

Uma experiência adicional pode ser feita com o equipamento funcionando em quaisquer das combinações de cores. Colocando-se a mão espalmada na frente do experimento com os dedos entreabertos e a sacudindo-a como se estivesse se despedindo de alguém, reproduzindo o efeito de um estroboscópio, é possível observar as cores individuais dos LEDs que, ao girarem, compõem a cor sintetizada. A ideia é tentar atingir, com o movimento da mão, uma sincronização da passagem das aberturas entre os dedos com o movimento dos LEDs nessa mesma direção. Quando essa sincronização é atingida, o tempo de exposição da luz dos LEDs, que acompanham o movimento da mão, torna-se superior ao da remanência visual, permitindo assim que o olho perceba os LEDs individualmente.

\section{Referências}

[1] R.B. Barthem, A Luz, Temas Atuais de Física (Editora Livraria da Física, São Paulo, 2005), $1^{\mathrm{a}}$ ed.

[2] "Plateau, Joseph Antoine Ferdinand - Complete Dictionary of Scientific Biography", disponível em http://www.encyclopedia.com/doc/ 1G2-2830903442.html, acesso em 22/2/2016.

[3] "Persistência Retiniana" disponível em https://precinema.wordpress.com/2009/ 10/28/persistencia-retiniana/, acesso em $93 / 2016$.

[4] G. Stolf, Princípios de Televisão Digital, disponível em http://www.lcs.poli.usp.br/ gstolfi/ PPT/APTV0315.pdf, acesso em 15/3/2016.

[5] I. Newton, Optica (Editora da Universidade de São Paulo, São Paulo, 2002), tradução, introdução e notas de André Koch Torres de Assis, 1a ed.

[6] A. Stockman, D. Macleod and N. Johnson, J. Opt. Soc. Am. A 10, 249 (1993).

[7] W.D. Wright, The Measurement of Colour (Hilger \& Watts, Londres, 1944).

[8] B.M.Q. Shaw, Evaluating the 1931 CIE Color Matching Functions, disponível em http://www.rit-mcsl .org/StudentResearch/ mshaw/CMF_Thesis.pdf, acesso em 10/3/2016.

[9] L.J. Jonathas, Uma Abordagem Experimental para o Ensino da Quantização da Luz. Dissertação de Mestrado em Ensino de Física, UFRJ, 2015. disponível em http://objdig.ufrj.br/12/teses/ 828142.pdf, acesso em 9/3/2016. 